\title{
Body Mass Index 19 to Less Than 21
}

National Cancer Institute

\section{Source}

National Cancer Institute. Body Mass Index 19 to Less Than 21. NCI Thesaurus. Code C138933.

Indicates a body mass index measurement greater than or equal to 19 but below 21 . 